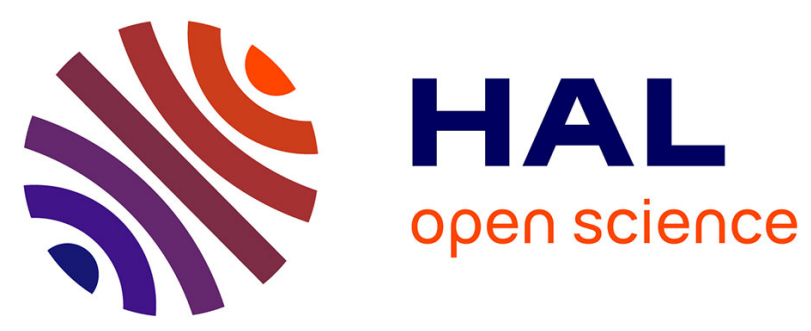

\title{
Hydraulic and Mass Transfer Performances of a Commercial Hybrid Packing: The RSP200X-Key Modelling Parameters for Gas Treatment Applications
}

Pascal Alix, John Roesler, Xavier Courtial, Gauthier Perdu, Michael Schultes

\section{- To cite this version:}

Pascal Alix, John Roesler, Xavier Courtial, Gauthier Perdu, Michael Schultes. Hydraulic and Mass Transfer Performances of a Commercial Hybrid Packing: The RSP200X-Key Modelling Parameters for Gas Treatment Applications. Chemical Engineering Transactions, 2018, 69, pp.697-702. 10.3303/CET1869117 . hal-01900571

\section{HAL Id: hal-01900571 \\ https: / hal-ifp.archives-ouvertes.fr/hal-01900571}

Submitted on 22 Oct 2018

HAL is a multi-disciplinary open access archive for the deposit and dissemination of scientific research documents, whether they are published or not. The documents may come from teaching and research institutions in France or abroad, or from public or private research centers.
L'archive ouverte pluridisciplinaire HAL, est destinée au dépôt et à la diffusion de documents scientifiques de niveau recherche, publiés ou non, émanant des établissements d'enseignement et de recherche français ou étrangers, des laboratoires publics ou privés. 


\title{
Hydraulic and Mass Transfer Performances of a Commercial Hybrid Packing: The RSP200X - Key Modelling Parameters for Gas Treatment Applications
}

\author{
Pascal Alix ${ }^{a}$, John Roesler ${ }^{a}$, Xavier Courtial $^{b}$, Gauthier Perdu $^{b}$, Michael Schultes $^{c}$ \\ ${ }^{a}$ IFP Energies nouvelles, BP 3, 69360 Solaize, France \\ ${ }^{\mathrm{b}}$ PROSERNAT Tour PACIFIC, 11-13 cours Valmy, 92977, Paris La Défense Cedex, France \\ ${ }^{c}$ RASCHIG GmbH, Mundenheimer Straße 100, D-67061 Ludwigshafen, Germany \\ pascal.alix@ifpen.fr
}

The use of the last generation of Raschig's structured packings, Raschig SuperPack (RSP) has been investigated for scrubbing columns operating at high liquid loads, for their potential to increase capacity while maintaining mass transfer efficiencies at high levels. IFPEN has measured pressure drops, flooding limits, liquid and gas side mass transfer coefficients and interfacial areas for the RSP 200X. Flooding limits were in agreement with literature, however at high liquid loads and for tested X-Style RSP they were 30-40\% lower than those calculated with the Winsorp Software. This indicates that extrapolation of flooding models should be used with caution to size column diameters for fluid systems and liquid loads that differ from those from which these models were derived. With the support of the present results a modified version of Winsorp has been elaborated for high liquid loads and X-Style RSP. RSP 200X develops a high interfacial area, close to the one of a standard $250 \mathrm{~m}^{2} / \mathrm{m}^{3}$ structured packing. One important difference however has been noted about the impact of the gas flowrate on the interfacial area. While for standard packings the gas flow rate is often considered to have only a small effect on area when operating below the loading point, the effect measured on RSP200X is significant and of the same order as for liquid load. Measurements of $k_{L} a_{e}$ further confirm that these latest generations of packings show different trends when compared to standard structured packings. Detailed characterization tests are therefore highly recommended to estimate the performances of these packings in terms of hydraulics and mass transfer properties. In some distant future, it is believed that CFD calculations (gas and gas/liquid) will help to better understand and model such phenomena.

\section{Introduction}

The latest generation of Raschig's structured packings RSP (Raschig Super-Pak) can be considered for scrubbing columns operating at high liquid loads, for a potential to increase hydraulic capacity while maintaining intensive mass transfer efficiencies. RSP packings are more open than standard high capacity structured packings (see figure 1b), and for that reason they are usually called hybrid packings. The RSP200X (Schultes, 2017) is a relevant case study since it can develop an effective area close to the one of $250 \mathrm{~m}^{2} / \mathrm{m}^{3}$ packings. In parallel it can handle high and wide range of liquid loads (from 10 to $120 \mathrm{~m}^{3} / \mathrm{m}^{2} / \mathrm{hr}$ ).

Experiments have been conducted with two different columns to measure hydraulic and mass transfer performances of the RSP200X. This paper gives some results that illustrate the performances of this hybrid packing, and highlights the need to consider the effect of gas flowrate on mass transfer rates.

\section{Experimental facilities / methods}

Two test columns available at IFPEN premises in Solaize (France) have been used for this work. The first one is a $146 \mathrm{~mm}$ inner diameter stainless steel column with a 3 meter bed height. It operates at room temperature and pressures from 1.2 to 2 bar abs. Liquid loads, $Q_{L}$, of $200 \mathrm{~m}^{3} / \mathrm{m}^{2} / \mathrm{h}$, and gas load factors, $F_{S}$, of $5 \mathrm{~Pa}^{0,5}$ can be reached if needed. This first column will be called D146 in this manuscript. The second one is a $1000 \mathrm{~mm}$ inner diameter transparent column with a 3 meter bed height. It operates at room temperature and pressure. 
Liquid loads of $100 \mathrm{~m}^{3} / \mathrm{m}^{2} / \mathrm{h}$, and gas load factors of $4 \mathrm{~Pa}^{0,5}$ can be reached if needed. This second column will be called D1000 in this manuscript.

Both columns (D146 and D1000) are used for most of the measurements. Hydraulic parameters (pressure drop, flooding limits) have been measured with air/water system. Effective area, $a_{e}$, has been measured with the absorption of $\mathrm{CO}_{2}$ from air into $\mathrm{NaOH}(0,1 \mathrm{~N})$ system, which leads to a pseudo-first order fast chemical reaction (Wang, 2015, Hoffmann et al., 2007). Liquid side mass transfer coefficient, $k_{L} a_{e}$, has been measured by absorption of $\mathrm{CO}_{2}$ diluted with air into a 3\%wt MDEA solution (Roesler et al., 2016) which leads to a slow chemical reaction. Gas side mass transfer coefficient, $k_{G} a_{e}$, has been measured in the $146 \mathrm{~mm}$ column only, by absorption of $\mathrm{SO}_{2}$ diluted with air into $\mathrm{NaOH}(2 \mathrm{~N})$ (Hoffmann et al., 2007) which leads to an instantaneous chemical reaction. For $k_{G} a_{e}$ measurements, the bed height is reduced to 2 blocks (about $0.4 \mathrm{~m}$ ), and a liquid pre-distributor is used. The experimental protocol has considered the end effects of the setup and they are subtracted in the conclusion: the $k_{G} a_{e}$ had been determined from measurements with and without packing. For all measurements, gas and liquid concentrations are measured at column inlet and outlet.

\section{Hydraulics performances}

Pressure drop and flooding limits were measured for $Q_{L}$ from 10 to $120 \mathrm{~m}^{3} / \mathrm{m}^{2} / \mathrm{h}$. IFPEN measurements have been compared to the results of Wang (2015) and the calculations from two versions of the Raschig software: "Winsorp" and "Winsorp 2017", the latter reflecting updates including this work. It should be noted that Wang used a 430mm inner diameter column with a bed height of $3.05 \mathrm{~m}$. This column will be called D430 in this manuscript. As shown in Figure 1a for $Q_{L}=60 \mathrm{~m}^{3} / \mathrm{m}^{2} / \mathrm{h}$, IFPEN and Wang results are in good agreement. The D146 results are a little bit staggered which indicates that there is not a major effect of diameter on the present measurements. Little by-pass at the wall and/or experimental error could explain a lower pressure drop with the $\mathrm{D} 146$ at $F_{s}=1,3 \mathrm{~Pa}^{0,5}$. However, the study has a discrepancy between the results and the ones given by the early version of Winsorp software (before 2017) which over predicts flooding limits by $30-40 \%$. Investigations with Raschig have shown that the software was based on distillation tests at the lower liquid loads only. The IFPEN tests have explored the higher loading rates and indicate that extrapolation of flooding models should be used with caution to size column diameters for fluid systems and liquid loads that differ from those from which these models were based on. With the support of the new results, a modified version of the software, Winsorp ("2017"), has been elaborated for high liquid loads and X-style RSP. Figure 1 indicates the performance determined in various IFPEN set-up's, by Wang, and tabulation by the two versions of Winsorp.

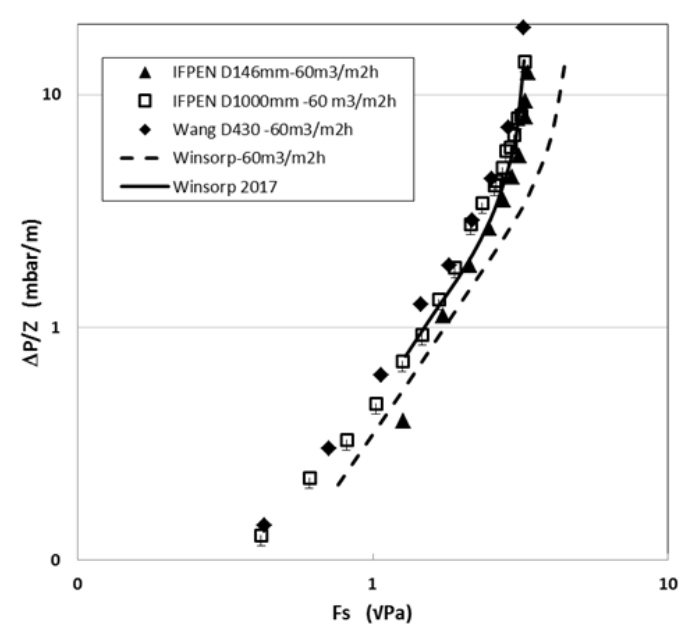

a/
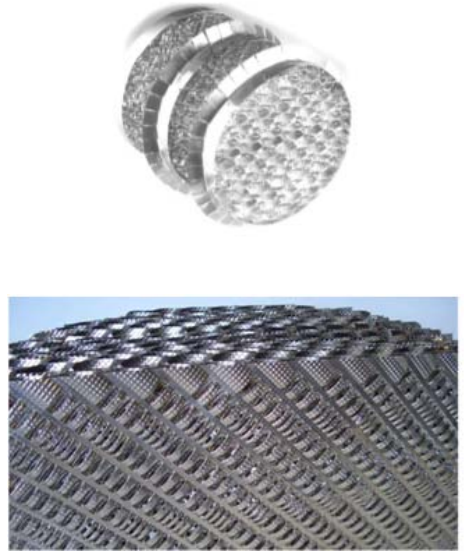

b/

Figure 1 : a/ Pressure drop of the RSP200X. Comparison of IFPEN measurements on D146 and D1000, with results of Wang (2015) on D430, and calculations of both Winsorp versions (original and revised in 2017). For $Q_{L}=60 \mathrm{~m}^{3} / \mathrm{m}^{2} / \mathrm{h}$. b/ Pictures of RSP packings.

\section{Mass transfer performances}

The experiment conducted at IFPEN has characterized the mass transfer parameters of RSP200X: interfacial area, mass transfer coefficients of the liquid phase, gas phase. 


\subsection{Effective area : $a_{e}$}

Figure 2 gives the ratio of effective areas measured by IFPEN relative to those of Wang (2015, D430), as a function of the ratio $Q_{L} / Q_{L, \text { ref }}$ for a fixed $F_{S}=1,5 \mathrm{~Pa}^{0,5}$. The latter is an intermediate value that is lower than the loading limit. It appears that IFPEN values can be considered in agreement with those of Wang since a $15 \%$ difference falls within typical experimental uncertainties (Hoffmann et al., 2007). However it has been found that the IFPEN values are systematically lower. Meanwhile, the figure 2 indicates that effective area measured in the D146 column is similar to the one measured in the $1000 \mathrm{~mm}$ column (within 5\%). Therefore the difference with the results of Wang cannot be attributed either to a diameter effect or to a model effect (thermodynamics and kinetics models are identical). An effect of the liquid distributor (Wang uses a fractal liquid distributor) or a difference in the temperature used for the chemical reaction rate could explain such differences.

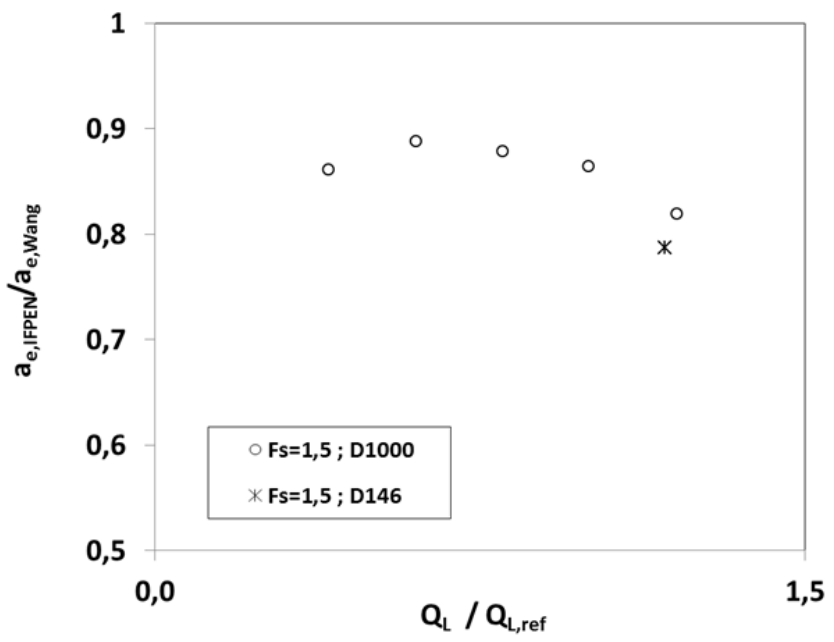

Figure 2 : Ratio of effective areas measured by IFPEN (with D1000 and D146) and by Wang (2015) on the $D 430$ as a function of the ratio $Q_{L} / Q_{L, \text { ref, }}$ at $F_{S}=1.5 \mathrm{~Pa}^{0,5} . Q_{L, \text { ref }}=60 \mathrm{~m}^{3} / \mathrm{m}^{2} / \mathrm{h}$.

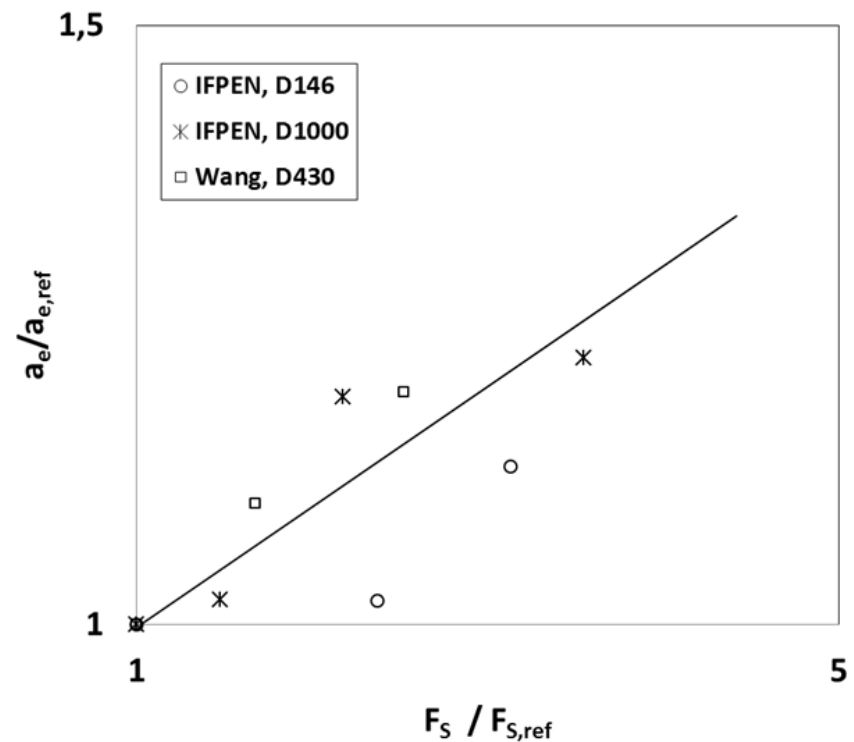

Figure 3 : Ratio of measured effective area to the one measured at $F_{S}=0,65 \mathrm{~Pa}^{0,5}$, as a function of $F_{S} / F_{s, \text { ref }}$ at a fixed liquid load of $Q_{L}=60 \mathrm{~m}^{3} / \mathrm{m}^{2} / \mathrm{h}$ for IFPEN and Wang (2015) results. 
For a fixed $Q_{L}=60 \mathrm{~m}^{3} / \mathrm{m}^{2} / \mathrm{h}$, Figure 3 gives the ratio $a_{e} / a_{e, \text { ref }}$ as a function of the ratio $F_{s} / F_{s, \text { ref }}$ for both IFPEN and Wang (2015) results, where $a_{e, r e f}$ is the effective area measured at $F_{S}=0,65 \mathrm{~Pa}^{0,5}$ at the respective columns. Figure 3 shows that the gas load impacts the effective area for the D430 and D1000 columns, $a_{e}$ could be increased by $20 \%$ (solid line). This was not expected since it cannot be explained by the hydraulics regime: the loading point is reached at $F_{s}=2,3 \mathrm{~Pa}^{0,5}$ for this liquid load (see Figure 1). The behaviour of the D146 is a little bit different, gas load effect is lower and not significant below a ratio of 2 . This specific point has been explained by a moderate diameter effect. The impact of the gas load on the effective area has been observed for some random packings (Wang et al., 2005), however it is not common for structured packings. Hybrid packings like RSP200X are considered between random and structured packings, this could explain present results. This seems to indicate that, for some hybrid packings, an effect of the gas load should be considered to improve the accuracy of correlative models of mass transfer parameters.

\subsection{Liquid side mass transfer : $k_{L} a_{e}$}

Figure 4 gives $k_{L} a_{e}$ values measured by IFPEN as a function of the ratio $Q_{L} / Q_{L, \text { ref, }}$ at $F_{S}=1.5 \mathrm{~Pa}^{0,5}$. Measurements are compared to those of Wang (2015). First, it should be noted that Wang uses the physical desorption of Toluene from water to measure $k_{L} a_{e}$. Thus the raw data from Wang should be corrected when the transfer of $\mathrm{CO}_{2}$ is used in experimental tests of $k_{L} a_{e}$. In that purpose, the raw data are multiplied by the ratio of the square root of liquid diffusivities of Toluene and $\mathrm{CO}_{2}$ into water, since there is no impact of the MDEA at 3\%wt. Figure 4 shows that IFPEN and Wang measurements are in reasonable agreement. On the other hand, the values from the D146 column are significantly lower than those from D430 and D1000 columns. This confirms the existence of a significant diameter effect on the liquid phase, whereas only moderate size effects are seen on hydraulic and effective area measurements. The hydraulic diameter of the RSP200X mesh is close to $0.02 \mathrm{~m}$, thus the ratio of the column to hydraulic diameter equals 7.3 for the D146. This value is lower than the one recommended by Olujic (1999) to eliminate size effects and could explain such results.

Figure 5 gives the ratio of the experimental $k_{L} a_{e}$ to the one measured at $F_{S}=0,5 \mathrm{~Pa}^{0,5}$, as a function of ratio $F_{S} / F_{s, \text { ref. }}$ The liquid load is fixed, $Q_{L}=60 \mathrm{~m}^{3} / \mathrm{m}^{2} / \mathrm{h}$. D1000 results have been selected since those from D146 are impacted by the column diameter. A gas load effect is clearly shown in Figure 6 where $k_{L} a_{e}$ increases by more than $20 \%$ for $F_{s}=2 \mathrm{~Pa}^{0,5}$. This is coherent with effective area results, and confirms the need to consider a higher than usual gas load effect for structured packings.

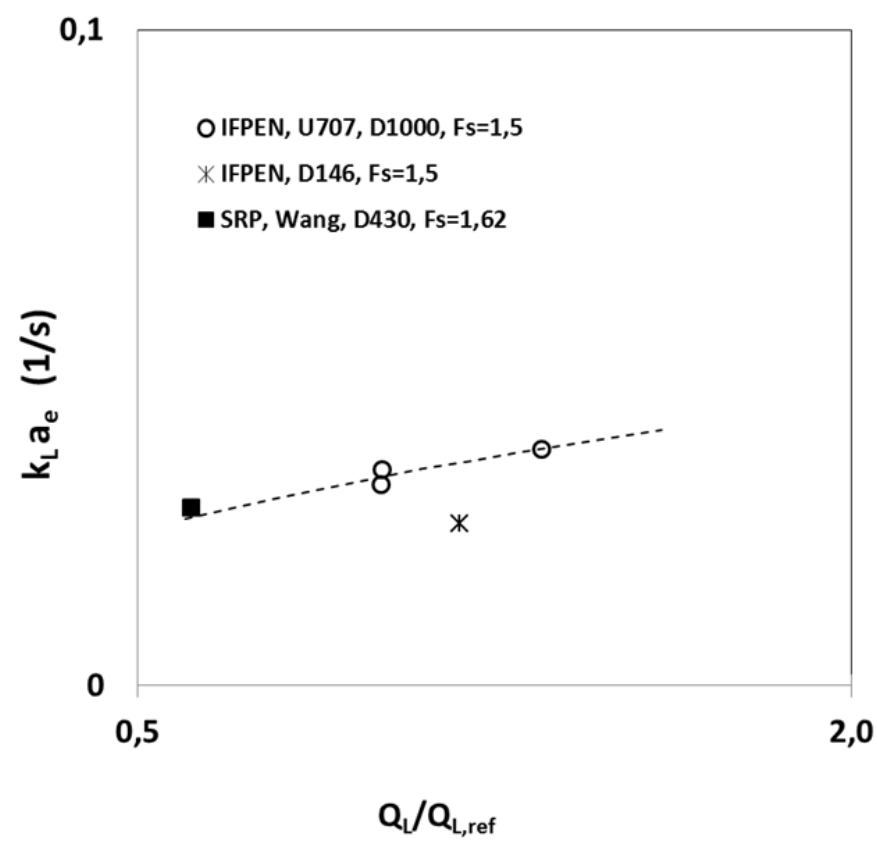

Figure $4: k_{L} a_{e}$ as a function of the ratio $Q_{L} / Q_{L, \text { ref, at }} F_{S}=1,5 \mathrm{~Pa}^{0,5}$. IFPEN measurements vs. Wang "corrected" measurements. $Q_{L, r e f}=60 \mathrm{~m}^{3} / \mathrm{m}^{2} / \mathrm{h}$. 


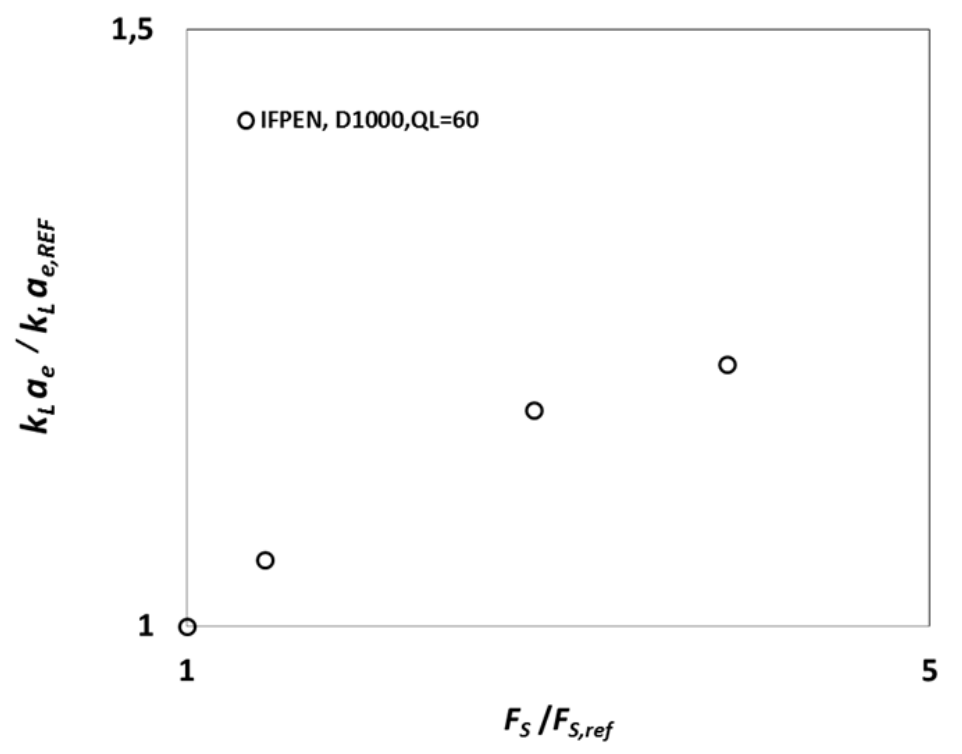

Figure 5 : Ratio of $k_{L} a_{e}$ with the one measured at $F_{S}=0.5 \mathrm{~Pa}^{0,5}$, as a function of $F_{S} / F_{S, \text { ref }}$ and at $Q_{L}=60 \mathrm{~m}^{3} / \mathrm{m}^{2} / \mathrm{h}$. IFPEN measurements (D1000).

\subsection{Gas side mass transfer : $k_{G} a_{e}$}

The $k_{G} a_{e}$ values have been measured in the D146 column (see chapter 2.). The IFPEN column is operated around 2 bar abs while the Wang column (2015) operates at atmospheric pressure. With these pressure differences, $k_{G}$ values cannot be compared directly. One should calculate the Sherwood number which considers the impact of the gas diffusivity, $D_{G, S O 2}$ :

$$
S h_{G}=\frac{k_{G} d_{e q}}{D_{G, S O 2}}
$$

For the present structured packing :

$$
d_{e q}=\frac{4}{a_{g}}
$$

$a_{g}$ is the geometric specific area of the RSP200X, which is equal to $200 \mathrm{~m}^{2} / \mathrm{m}^{3}$. It must be noted that IFPEN $k_{G}$ values have been calculated by dividing $k_{G} a_{e}$ with interfacial areas measured in the D146 column which differ slightly from those measured with the D1000 column (see 4.1) but are coherent with the $k_{G}$ a values.

Figure 6 gives the Sherwood number as a function of the gas Reynolds number, and compares IFPEN values to those of Wang (2015). The gas Reynolds number takes into account the impact of the pressure on the hydraulics :

$$
R e_{G}=\frac{\sqrt{\rho_{G}} F_{S} d_{e q}}{\mu_{G}}
$$

Where $\mu_{G}$ is the gas dynamic viscosity (Pa.s), and $\rho_{G}$ is the gas density $\left(\mathrm{kg} / \mathrm{m}^{3}\right)$.

Figure 6 shows that IFPEN measurements are in good agreement with Wang measurements. This indicates that there is a negligible diameter effect on $k_{G}$ which was not the case for the $k_{L}$ (see 4.2). The present measurements could therefore be used to build correlations for bigger columns. At $R e_{G}=3000$, the Wang value is not in agreement with other ones and seems to be too low. This could be explained by the fact that at such high gas flowrates the $\mathrm{SO}_{2}$ concentrations in the gas leaving the packing bed become very low such as to generate higher experimental errors. Upon extrapolation to the intercept, the Sherwood number follows a power law dependency of 0,83 relative to the gas Reynolds number, which is in agreement with a majority of publications that recommend 0,8 (Wang et al., 2005). This also confirms the fact that there is no significant diameter effect on present results. 


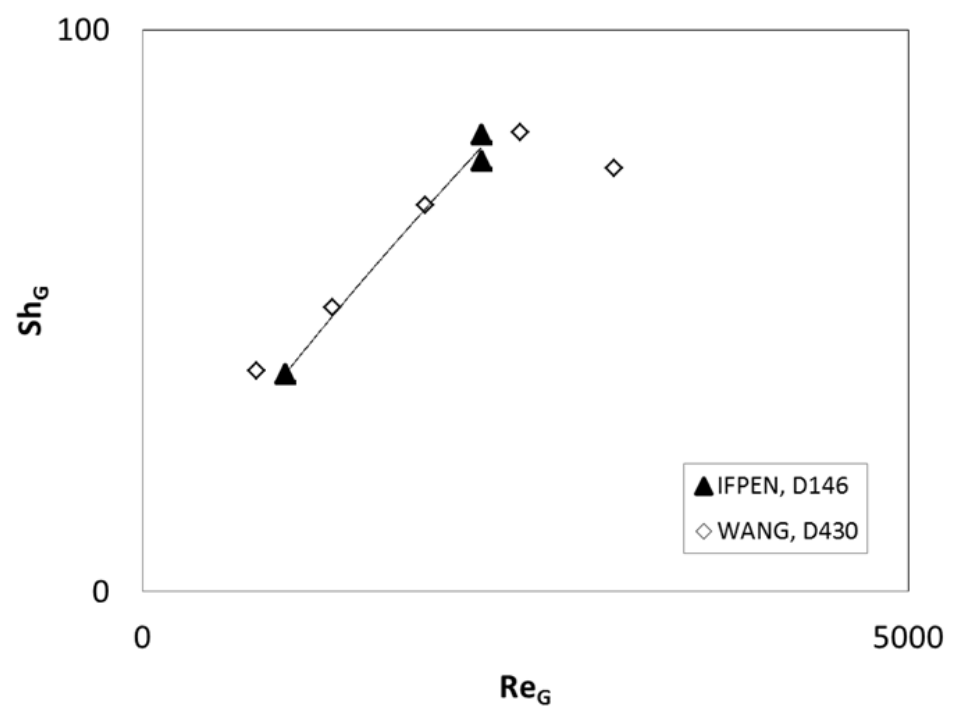

Figure 6 : Gas Sherwood number as a function of the gas Reynolds number. IFPEN measurements (D146) vs. Wang measurements (D430, 2015).

\section{Conclusions}

Experiments with the RSP200X Raschig hybrid structured packing have been performed in two test facilities with respective inner diameters of 146 and $1000 \mathrm{~mm}$. Pressure drop, flooding limits, and mass transfer parameters have been measured with system models. Hydraulics tests show that extrapolation of available flooding models should be used with caution to size column diameters, for fluid systems and liquid loads that differ from those from which these models were derived. With the support of present results, a modified version of Winsorp ("2017") has been elaborated by Raschig for high liquid loads and X-style RSP. Mass transfer tests show that a gas velocity effect should be consider on interfacial area of hybrid packings like RSP, which was not expected for any structured packing. This is confirmed by $k_{L} a_{e}$ measurements. A diameter effect is highlighted for the D146 column, however this effect is on the liquid phase only $\left(k_{L}\right)$. For the gas phase $\left(k_{G}\right)$ this diameter effect becomes negligible. Finally, the present test results are in good agreement with those of Wang obtained with a $430 \mathrm{~mm}$ inner diameter column and other system model used to determine $k_{L} a_{e}$.

\section{References}

Hoffmann A., Mackowiak JF., Gorak A., Haas M., Löning JM., Runowski T., Hallenberger K., 2007, Standardization of mass transfer measurements. A basis for the description of absorption processes, Chem Eng. Res. And Design, 85(A1), 40-49

Olujic Z., 1999, Effect of column diameter on pressure drop of a corrugated sheet structured packing, TransIChemE, 77, 505-510.

Roesler J, Royon-Lebeaud A, Alix P. Liquid side mass transfer coefficient measurements in tall structured packing beds by reactive absorption with dilute MDEA solutions. Paper Presented at 2016 AIChE Annual Meeting, San Francisco, CA, USA, November 13-18, 2016, Paper n8467941.

Schultes M., 2017, Raschig Super Pak. A new packing structure with innovative advantages. Product Bulletin 501.

Wang GQ., Yuan XG., Yu KT., 2005, Review of mass transfer correlations for packed columns, Ind. Eng. Chem. Res., 44, 8715-8729

Wang, 2015, Mass transfer coefficient and effective area of packing. Thesis manuscript, The University of Texas. 